\title{
EUROSON 2018 Poznan, Poland
}

\section{EUROSON 2018 in POZNAN (The 30th EUROSON Congress of the EFSUMB)}

We have the great pleasure to invite you to the 30th EUROSON Congress of EFSUMB, which will take place in Poznan 6 - 9 September 2018. The Congress will be held in the Congress Centre of the Poznan International Fair simultaneously with the XIV Congress of Polish Scientific Society of Ultrasonography.

\section{Ultrasound Education Center for Students - EUROSON 2018}

“Let's Make Ultra-Future Together" Thursday:

15:00 - 16:30 Opening Ceremony

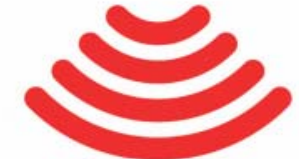 \\ EUROSON \\ 6-9.09.2018, Poznań, Poland}

\section{Friday:}

9:00 - 10:00 “Test Your Knowledge" Ultrasound Anatomy of the Abdomen 10:00 - 11:45 “Test Your Skill” - Hands-onTraining with Real-Time Examination Guide: Abdomen

11:45 - 12:00 Q \& A with The Expert 12:00 - 13:00 "Test Your Experience" Ultrasound-based Differential Diagnosis Challenge: Abdomen Part I

13:00 - 15:00 Lunch (Hands-on-Training) 15:00 - 16:00 “Test Your Experience" Ultrasound-based Differential Diagnosis Challenge: Abdomen Part II

16:00 - 17:00 Guest Presentation

\section{Saturday:}

9:00 - 9:45 Tips \& Tricks for Abdominal Ultrasound (with Hands-on-Training) 9:45 - 10:00 Q \& A with The Expert 10:00 - 11:00 "Test Your Knowledge" Ultrasound Anatomy: Thyroid, Neck, Mediastinum, Lungs

11:00 - 12:00 Guest Presentation 12:00 - 13:00 “Test Your Skill” - Hands-onTraining with Real-Time Examination Guide: Thyroid, Neck, Mediastinum, Lungs Part I 13:00 - 15:00 Lunch (Hands-on-Training)

\section{Sunday:}

9:00 - 10:00 “Test Your Skill” - Hands-onTraining with Real-Time Examination Guide: Thyroid, Neck, Mediastinum, Lungs Part II 
10:00 - 12:00 “Test Your Experience” Ultrasound-based Differential Diagnosis Challenge: Thyroid, Neck, Mediastinum, Lungs

12:00 - 13:00 Tips \& Tricks: Thyroid, Neck, Mediastinum, Lungs

12:45 - 13:00 Q \& A with The Expert

13:00 Closing Ceremony

\section{UltraSQAN - Ultrasound Student Quiz for Advanced and Novice at EUROSON} 2018

We invite everyone interested in testing their ultrasound knowledge to take part in the UltraSQAN - Ultrasound Student Quiz for Advanced and Novice. The competition will be conducted in two categories: a team of 3-person groups of students from all over Europe, and an individual one in which every participant of the EUROSON Congress can take part. The tournament will be conducted in two parts, theoretical and practical. At first, teams and individual participants will answer a number of questions regarding ultrasound anatomy, ultrasound physics, basic diagnostic challenges and more... This phase will be carried out using the Kahoot! App, therefore it is necessary to have an electronic device with Internet access (i.e. smartphone) on which the free Kahoot! App has been installed! An individual winner will be selected and receive a surprise gift from the organizers of the EUROSON Congress. The theoretical part will also allow us to select two best student teams that will cross transducers in the practical part.
In the second part of the Quiz, both teams will have the opportunity to present their skills by performing a number of tasks assigned to them by the Competition Jury. Victory will be determined by precision, knowledge of various examination techniques, ingenuity and time of task completion. The second stage will select three Best Young Sonography Adepts in Europe.

Three-person teams of students wishing to take part in the Quiz are invited to send their application to: euroson2018@mtp.pl (please write "UltraSQAN" in the title of the application). Individual participants will be able to take part in the Competition without prior registration.

The competition will be conducted in English. 